\title{
THE SECOND INTERNATIONAL SYMPOSIUM ON ARCHAEOLOGY AND ${ }^{14} \mathrm{C}$
}

\section{RENEE KRA}

The Second International Symposium on Archaeology and ${ }^{14} \mathrm{C}$, September 7-11, 1987, Groningen, The Netherlands was a most successful forum for the exchange of information and ideas among archaeologists and radiocarbon daters. The sincere intent of the organizers to achieve closer understanding and appreciation between the two disciplines was apparent throughout the conference. Indeed, even the conference title was changed from ${ }^{114} \mathrm{C}$ and Archaeology" to "Archaeology and ${ }^{14} \mathrm{C}$."

An egalitarian tone was established at the outset, when WG Mook introduced the opening session on radiocarbon data bases as probably the least interesting scientifically, but, nevertheless, one of the most important current topics for radiocarbon daters and users.

The most controversial and universally problematic theme that continued through the week was "The Calibration Issue," both in terms of "the red volume of Mrs Kra" (to quote Dr Suess) as well as the difficulties encountered in deriving calendrical ages from the calibration curves. Unfortunately, neither Minze Stuiver nor Gordon Pearson, the chief architects of the curves, were present to explicate and discuss conversion procedures as well as their quantitative and qualitative merits.

Another key topic of debate was conventions of terminology in reporting radiocarbon determinations. After much animated discussion, the participants reached a consensus on maintaining the cal AD/BC (cal BP) nomenclature recommended by the Trondheim conference.

Henrik Tauber summed up the conflicts between archaeologists and radiocarbon dates with an appropriate if not chauvinistic analogue about women: "Life is difficult with them but impossible without them."

In summary, the sessions focused on current issues in radiocarbon dating related to the field of archaeology - the importance of The International Radiocarbon Data Base, calibration problems and interpretations, inter-laboratory comparisons of precision, treatment of samples, Accelerator Mass Spectrometry (AMS), and terminology.

The pervading atmosphere was exciting, sometimes electric, always infused with good humor and good taste. And allusions to "loose people" and a "fog over the British Isles" will linger in our fond memories. 